\title{
Tentative Study of Eco-Friendly Nickel Metal Battery
}

\author{
Vijayvenkatesh Chandrasekaran
}

Department of Structural Engineering, SASTRA University, Thanjavur, India

\author{
Email address: \\ ramathutham@gmail.com
}

\section{To cite this article:}

Vijayvenkatesh Chandrasekaran. Tentative Study of Eco-Friendly Nickel Metal Battery. Science Research. Vol. 7, No. 5, 2019 , pp. 64-67. doi: $10.11648 /$ j.sr.20190705.12

Received: March 5, 2019; Accepted: April 11, 2019; Published: October 20, 2019

\begin{abstract}
The most recent battery manufacturers are the high electronic waste and after unworkable. And that battery considerations waste products that considerations for E-waste and causes of globalization, pollutant nature and created many diseases. That consider to identified the nickel batteries. That battery is high saving energy and durability of lives spans. It rechargeable fluid (Molten Salt). It is highly workable to Direct and alternative current it any damaged extra structures some corroded in nature dismantled to re-manufacturing and controlled of E-wastes. It highly controlled electronics waste and globalization effects. That paper present to the experimentally to build the two types of nickel battery (3.5 volts and 200v). Check the work duration, withstanding capacity in rechargeable over the lifetime duration reviews. Finally estimating quantity analysis report for 3.5 volt single and $200 \mathrm{v}$ inverter batteries.
\end{abstract}

Keywords: Nickel Metal Plates, Molten Salt, Sealant Box, Insulation Coat, Voltage Duration, Estimating Values

\section{Introduction}

Rechargeable batteries and liquid favourable batteries are convinced to transports and heavy grinding works for D and A current supply stations \& electronics (laptops, phones, and other electronics goods) are usages [1]. It worked effectively and short duration times. And investment is high and efficient is low productivity [11]. It depends upon materials of battery contents for some other examples (lithium, cadmium, cobalt, iridium, thorium). Are the radioactive materials are used to combine to manufacture the certainly advanced batteries [6]. Lithium batteries are high saved energy and short durations. Cadmium batteries are high energy and power savings and long durations but are considerations cost high productions and created E-waste problems [8]. Cadmium rechargeable batteries are most used in satellite, supersonic missiles, and other defence purposes. Production process faced at lots of problems (guaranteed safety assurance). Cadmium batteries are sometimes used in satellite phones and radars [3]. That same equally problems are faced at the Iridium, thorium material batteries [7]. That main reasons for usage at the cobalt and cadmium that consider the lightweight materials compact design and worked ruffed citation works [5]. But nickel batteries are works in some ways and better durability for normal wages. It mainly controlled E-waste problems and better conveyed every place it assured the durability of smart lineages [10]. Mechanical worked with easy ways and should be compacted design the illustration of using works. It highly benefits from modern batteries compared to another. Protections of explosions in sudden changeable climatic conditions [2]. It to better normal usages eco-friendly in it better stays of environmental conditions. And refilling properties fluids in power status and long durations withstand able of compared to cadmium. It weight compared to so heavy in nickel material depends upon the volume of sizes and power storage status.

\section{Materials and Methods}

\subsection{Materials}

In experimental values of testing, materials are nickel plates required rectangular sizes $(30 \mathrm{~mm}$ into $15 \mathrm{~mm}$ ). Because the nickel is compound trihalophosphines. Nickel is an oxide ion its can be stabilized by sigma donor ligands such a thioh and phospines [12]. And is prevent in nickel oxide hydroxide [13]. Which is used to mostly rechargeable batteries, including the combination of other materials like nickel-cadmium, nickel-iron, nickel hydrogen and nickel metal hydride and it is used by certain manufactured lithiumion batteries rare oxidation state, application wise nickel is a 
very a small amount of compound is known to rendezvous [14].

\subsection{Thickness of Plate}

Experimentally chosen the nickel plate is $2 \mathrm{~mm}$ thickness (figure 1). Because it is a compacted design model batteries. And another important evaluation is nickel plate decide on criteria is an allergic contact dermatitis it contains stainless steels [15]. Mostly testing is used in high sulphur nickelcontaining stainless steels plates (303) refer AISI 304, 316L, 303 and 430 type stainless steel [16]. And provided the required number of steel plate used in that experiments to build on the batteries.

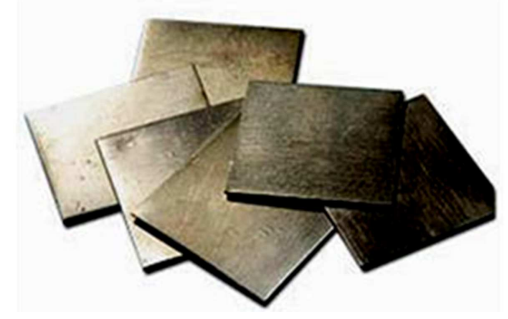

Figure 1. $2 \mathrm{~mm}$ thickness of nickel metal plate.

\subsection{Numbers of Longer Plates \& Shorter Plates}

Two number of long rectangular plates its arranged in top and bottom sides as like shown in figure 2. And three numbers of shorter rectangular plates provided in the inter between part of two longer plates. That arrangements certain gap is provided in plate assemble since fillet provisions. These plate arrangements are both types of nickel metal batteries $(3.5$ and $200 \mathrm{v})$.

\subsection{Enclosed Sealant Gad Rages}

$1 \mathrm{~mm}$ thickness of the tin materials gadget box covering. (Box created the electrical welding shops), External thin coverage coats, Insulations coats $0.156 \mathrm{~mm}$. The thin coat of insulations bands protections of power loss.

\subsection{Molten Salt}

It's a molten salt is a rechargeable configuration sodium sulphur molecular formulas of $\mathrm{Na} 2 \mathrm{~s}$ its properties of outrageous concentration-dehydration and oxidation properties [17]. And different such as metallic contact progression or lead chambering process in a batteries usages [18].

\subsection{Methods}

The shortened experimental methods availability of collections of materials and finished the works. The methodology of working values cutting plate used to power saws and filling the accurate sizes [4]. (Jobs schedules are taken that job is 1.5 weeks). Arranged the plates odder and enclosed tin seal. And after pouring Molten salt one ways cavity points closed sealant. It covered insulations coats tight the sealants (figure 2).

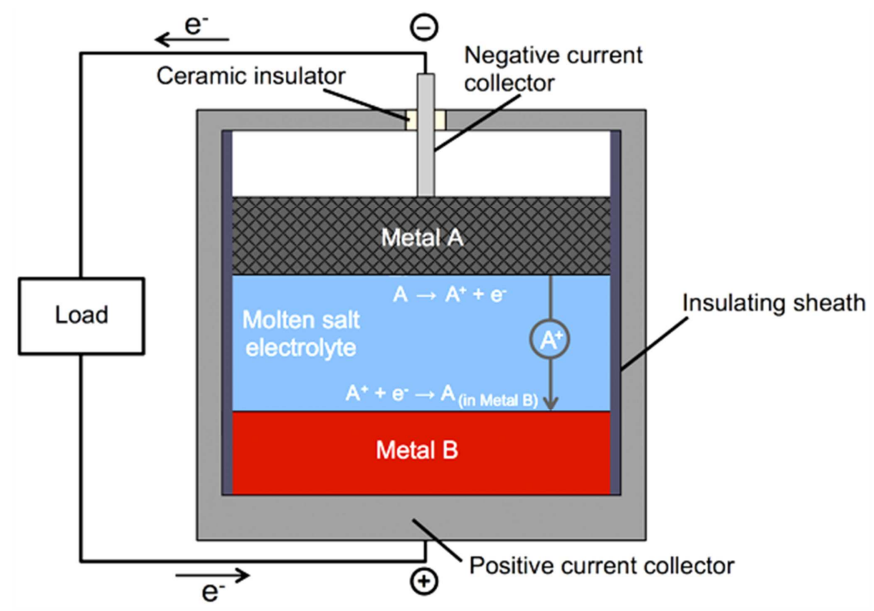

Figure 2. Nickel battery En-Sealed methods sample.

And after complications 30minutes and emitted power 3.5volt batteries. Normal experimental structural batteries design goes into successful emitted the nodal (+\&-) ranges. It refers the Figure 3 patterned to SEM nanostructures high effective values and implemented to nanotech configuration batteries.
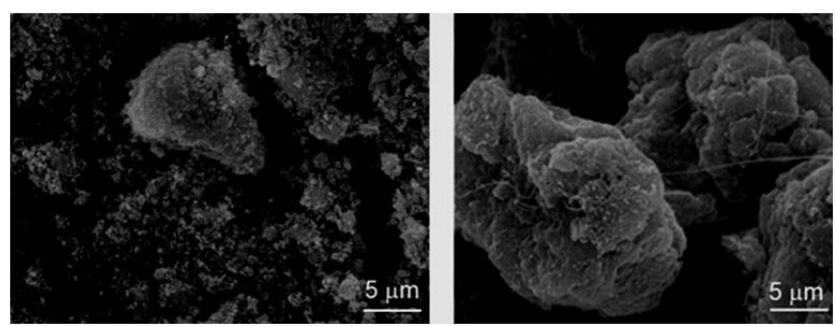

Figure 3. Scanning electron microscope (SEM) micrographs of $\alpha-\mathrm{Ni}(\mathrm{OH}) 2$ prepared by the $\mathrm{Ni}-2$.

\section{Result and Discussion}

\subsection{Voltage Durations of Nickel Metal Batteries}

_ using duration of hours in (h)

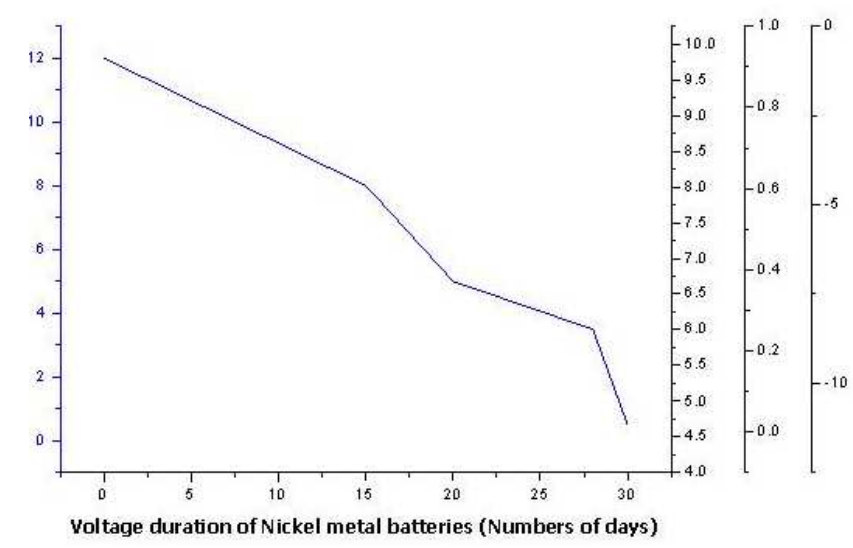

Figure 4. Voltage durations of nickel on battery. 
Figure 4 represented to voltage durations in monthly reviews. The experimental ranges of nickel metal rechargeable $(3.5 \mathrm{~V})$ batteries are durations power losses in the days (0-30 days). It refilled the molten salt liquids and again the duration status extends of months. Its easy handle and replaced the site situations of modelling work. The experimental works result from voltage power DC status low depend upon the usage of fields. These output values are taken to the identified the light, wall clocks, night Lamps.

\subsection{With Stand Capacity and Duration in Numbers of Times Rechargeable in Nickel Metal Batteries}

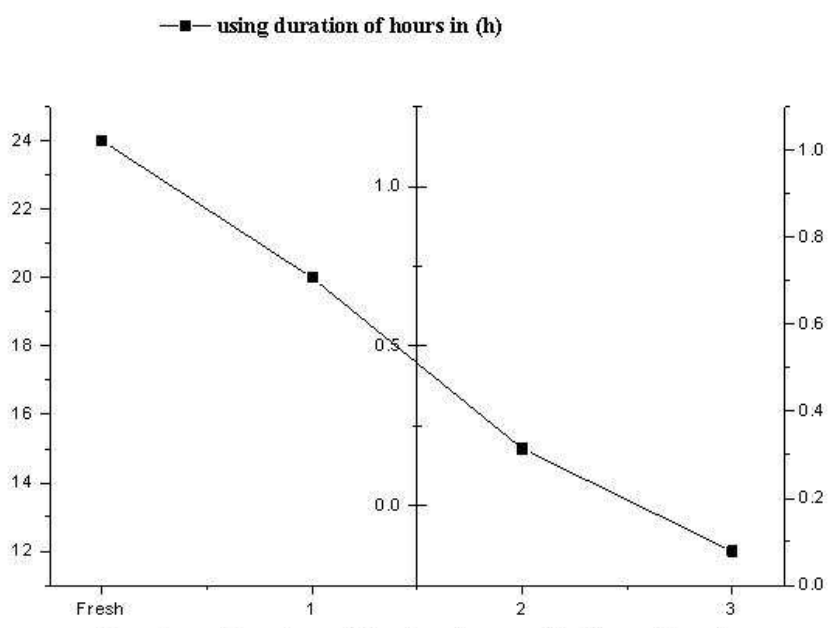

Experimental review of duration in year of battery. (Years)

Figure 5. Experimental review of duration in year of battery.

Figure 5 represented to experimental values of yearly reviews. In this case, other methods systems are followed to elaborated the DC current of inverter batteries $200 \mathrm{~V}$. It followed the same procedures for 3.5 volts batteries. Design procedures in nickel plates are exit level of shapes and sizes. Materials: $1(300 \mathrm{~mm})$ into $0.5(150 \mathrm{~mm})$ feet sizes, 4-long plates, 0.5 into 0.25 feet sizes 6 -short plates. $3 \mathrm{~mm}$ thickness plates provided. The sealed box is a $2 \mathrm{~mm}$ thickness of tin material it enclosed the structure. Insulations coats: $0.156 \mathrm{~mm}$ coats. Provided in external coverage's. Methods, (That same procedure for $3.5 \mathrm{~V}$ battery). The shortened experimental methods availability of collections of materials and finished the works. The methodology of working values cutting plate power saws, and filling the accurate sizes. (Jobs schedules 2-weeks). Arranged the plates odder large extend plates $(300 \mathrm{~mm}$ into $150 \mathrm{~mm})$ provided top and bottoms and other small (0.5into 0.25 feet) sizes arranged in intermediated and enclosed tin seal [9]. And after paste dry molten salt sulphur one ways cavity points and after closed sealant. It covered insulations coats tight sealants. And subsequent to complications 30minutes and emitted power in a battery. Normal experimental structural batteries design goes into successful emitted the nodal (+\&-) ranges. It patterned to CNC macro form structures high effective values and implemented to macro DC batteries.

\subsection{Estimations Quantity Analysis Report for 3.5 Volt, Single Battery}

The $2 \mathrm{~mm}$ thickness of nickel plates $=1$-plates sizes is 1 into 1.5 feet, it required 5 numbers of plates, ( 13 drops $\approx 0.52$ mile gram) Non-carbon petroleum fluids infill. And welding works of nickel plates: 2hours, maximum workshops job done in 5hours, Total experimental obligation process values for single nickel battery required to build in economic time periods. For consumptions mass productions for nickel material nano forms, structures battery is actual market rate is consumed. Comparisons for normal lithium rechargeable battery is the most reliable and economical assessment to nickel metal batteries.

\subsection{Estimation Quantity Analysis Report for 200v Inverter Battery}

The $2 \mathrm{~mm}$ thickness of nickel plates required 4 numbers, And $3-\mathrm{Kg}$ of molten salt essential filling in sealed box, Filling and welding works of nickel plates is taken maximum time period is 4hours, Total experimental obligation process values for single nickel $200 \mathrm{v}$ battery, required build in economic time periods (quality job works is done in the tentative studies). Mass productions of nickel material form structures are a dreadfully fast manufacturing process, the battery is actual market rate is consumed.

\section{Conclusions}

Nickel metal batteries are production system to inexpensive market rates. It extremely expendable power with comparable the traditional battery length time. however, it ends to the life of batteries doesn't cause for corrosion and it re-manufacture and replacement and once more to again use. Nickel battery is another name of the organic radical battery. And most of the battery waste in a very created heap of hot issues, however, this battery is employed in change state liquid usage, from high performances like atomic number 48. And eventually, additional economic compared current damage batteries.

\section{Acknowledgements}

These paper effort own interest and supported by my university professors. And to him for the patient guidance and support to my cross major research work.

\section{References}

[1] Sada, K., Senthilkumar, B., \& Barpanda, P. (2018). Layered $\mathrm{Na} 2 \mathrm{Mn} 3 \mathrm{O} 7$ as a $3.1 \mathrm{~V}$ Insertion Material for Li-Ion Batteries. ACS Applied Energy Materials, 1.(12), 6719-6724.

[2] Begg, K., van der Woerd, F., \& Levy, D. (2018). Best corporate responses to climate change: opportunities for converging climate and biodiversity protecting solutions. In The Business of Climate Change (pp. 61-74). Routledge. 
[3] Hernandez-Castro, J., \& Avoine, G. (2016, April). Cryptanalysis of ubiquitous computing systems. In 2016 18th Mediterranean Electrotechnical Conference (MELECON) (pp. 1-4). IEEE.

[4] Singh, G., Lakhi, K. S., Ramadass, K., Indirathankam, S. C., \& Vinu, A. (2019). High Performance Biomass derived Activated Porous Biocarbons for Combined Pre-and PostCombustion CO2 Capture. ACS Sustainable Chemistry \& Engineering.

[5] Ryu, S., Lee, S., Jung, J., Lee, J., \& Kim, Y. (2019). Micromechanics-based homogenization of the effective physical properties of composites with an anisotropic matrix and interfacial imperfections. Frontiers in Materials, 6.

[6] Wang, B., Ryu, J., Choi, S., Zhang, X., Pribat, D., Li, X., ... \& Ruoff, R. S. (2019). Ultrafast-Charging Silicon-Based CoralLike Network Anodes for Lithium-Ion Batteries with High Energy and Power Densities. ACS nano.

[7] Hanna, R., Gross, R., Speirs, J., Heptonstall, P., \& Gambhir, A. (2015). Innovation timelines from invention to maturity. UK Energy Research Centre.

[8] Zhang, C., Qiao, Y., Xiong, P., Ma, W., Bai, P., Wang, X., ... \& Zeng, J. H. (2019). Conjugated Microporous Polymers with Tunable Electronic Structure for High Performance Potassium-Ion Batteries. ACS nano.

[9] Lodovico, H. L. The role of the electrolyte on the lithiumsulfur battery electrochemistry.

[10] Awasthi, A. K., Wang, M., Wang, Z., Awasthi, M. K., \& Li, J.
(2018). E-waste management in India: A mini-review. Waste Management \& Research, 36 (5), 408-414.

[11] Hagos, T. T., Thirumalraj, B., Huang, C. J., Abrha, L. H., Hagos, T. M., Berhe, G. B., ... \& Hwang, B. J. (2019). Locally Concentrated LiPF6 in Carbonate-based Electrolyte with Fluoroethylene Carbonate as a Diluent for Anode-Free Lithium Metal Battery. ACS applied materials \& interfaces.

[12] Königsberger, E. (2019). Guidelines for the measurement of Solid-Liquid solubility data at atmospheric pressure.

[13] Wu, M. S., Sie, Y. J., \& Yang, S. B. (2019). Hollow mesoporous nickel dendrites grown on porous nickel foam for electrochemical oxidation of urea. Electrochimica Acta, 304, 131-137.

[14] Kelder, E. M. (2019). Materials for Electrochemical Energy Storage Devices. Critical Materials: Underlying Causes And Sustainable Mitigation Strategies, 5, 53.

[15] Heim, K., \& Basketter, D. (2018). Metal Exposure Regulations and Their Effect on Allergy Prevention. In Metal Allergy (pp. 39-54). Springer, Cham.

[16] Cardarelli, F. (2018). Ferrous metals and their alloys. In Materials Handbook (pp. 101-248). Springer, Cham.

[17] Amendola, S., \& Sharp-Goldman, S. (2019). U.S. Patent Application No. 16/154,075.

[18] Iqbal, M. Z., Rehman, A. U., \& Siddique, S. (2019). Recent developments in graphene based novel structures for efficient and durable fuel cells. Journal of Energy Chemistry. 